\title{
¿ORGANIZACIONES NO GUBERNAMENTALES INTERNACIONALES O “TRANSNACIONALES”?
}

\section{"INTERNATIONAL NON-GOVERMENTAL ORGANIZATIONS OR MULTINATIONAL NON GOVERNMENTAL ORGANIZATIONS?"}

\author{
Marc Jean Dourojeanni ${ }^{1}$
}

\begin{abstract}
Resumen
Se analiza el cambio de actitud progresivo de las principales ONGs internacionales ambientales que permite calificarlas ahora de "ONGs transnacionales", debido a que (1) se incorporaron a nivel nacional, (2) ejecutan directamente gran parte de sus programas y proyectos, (3) actúan como intermediarios en el manejo de fondos del exterior y (4) compiten contra las ONGs nacionales para la obtención de fondos nacionales y del exterior. Se discuten sus consecuencias negativas para el movimiento ambiental de América Latina, entre ellas: (1) competición desigual para la recaudación de fondos internacionales y locales; (2) erosión del dinero disponible para las operaciones debido a la intermediación estéril, (3) debilitamiento de las ONGs ambientales nacionales. Se concluye que gran parte del problema es responsabilidad de las propias ONGs nacionales que no han sabido mantener su independencia política y financiera ni negociar de igual a igual con las ONGs internacionales. Se proponen medidas concretas para resolver los problemas identificados.

Palabras clave: organizaciones no gubernamentales (ONGs) internacionales, ONGs nacionales, ambiente, relaciones, comportamiento, competencia, financiamiento, futuro
\end{abstract}

\begin{abstract}
Over the past twenty years the most important international NGOs have changed their behavior with regard to their work in Latin America. Their new approach can be qualified as "transnational" as: (1) they are becoming incorporated in the countries where they operate, (2) they directly execute a growing portion of their programs and projects, (3) they are becoming expensive intermediaries for external funding and (4) they directly compete against national NGOs for international and local funding. The consequences of this new approach are negative for the LatinAmerican environmental movement as: (1) it establishes a disproportionate competition to obtain funding, (2) it is the cause of a significant erosion of the funding for environment as a consequence of useless intermediation and, (3) it is weakening national NGOs. It is established that national NGOs are also responsible for the current situation as they were unable neither to keep their political autonomy nor to collect enough local funding as to maintain essential administrative independence. Several recommendations are proposed to contribute to the solution of the identified problems.
\end{abstract}

Key words: non-governmental international organizations (NGOs), national NGOs, relationships, behavior, financing, future

\section{Introducción y contexto}

Las relaciones entre las organizaciones no gubernamentales (ONGs) ambientales internacionales y las nacionales o subnacionales de América Latina pasaron, en los últimos 25 años de historia, de la euforia a la decepción por parte de estas últimas. Las razones de esta situación son diversas y no son exclusivamente responsabilidad de las ONGs internacionales aunque, como se sustenta en este artículo, la principal sea el cambio de comportamiento de la mayor parte de las grandes ONGs de actuación mundial que dejaron de ser internacionales para se transformar en transnacionales.

Lo importante es que esta situación está dificultando seriamente las relaciones de trabajo entre instituciones ambientales que deberían cooperar, generando conflictos innecesarios y malgasto de talentos y de recursos escasos. Peor aún, la situación actual está debilitando seriamente los movimientos ambientales nacionales al haber generado una competencia desleal y desigual entre éstos y las ONGs transnacionales.

En este artículo se analiza y discute la génesis y la situación actual del problema citado y, en especial, sus múltiples facetas y consecuencias y, finalmente, se mencionan las principales recomendaciones que se derivan del análisis para las ONGs nacionales y para las internacionales. Este tema no es realmente nuevo. Apenas por citar algunos trabajos, fue analizado por Myers \& Bucher (1989), Hellinger (1997) y por 
Chapin (2004). Sin embargo, este trabajo aborda aspectos diferentes o, por lo menos, lo hace con un enfoque distinto $\mathrm{y}$ desde una perspectiva latinoamericana.

A este punto es importante definir lo que se considera, en esta nota, como "internacional" por oposición a lo que es "transnacional”. Una organización internacional es la que actúa en más de un país, en principio sin interferir en los asuntos internos ni ejecutar directamente acciones en estos. Una organización transnacional también actúa en más de un país pero lo hace a través de su incorporación formal en estos, con la misma libertad de acción que la ley otorga a las nacionales. Ejemplos claros de esas diferencias son, de una parte, las agencias de las Naciones Unidas o los bancos multilaterales de desarrollo que, típicamente, son internacionales y, de otra, las grandes empresas de actuación mundial, como pueden ser la Coca Cola, la Siemens o la Shell, que se incorporan en los países y actúan en estos como si fueran organizaciones nacionales.

De otra parte, el texto trata esencialmente del comportamiento de tres ONGs internacionales muy importantes: World Wildlife Fund, hoy World Wide Fund For Nature (WWF), The Nature Conservancy (TNC) y Conservation Internacional (CI). Sin embargo, mucho de lo que se dice sobre ellas es válido, en diferentes proporciones, para varias otras ONGs de influencia mundial, como Green Peace y Friends of the Hearth, entre otras. Las tres ONGs citadas son las mayores por los recursos a su disposición y, dos de ellas (WWF y TNC), son de larga actuación en América Latina.

\section{Evolución del movimiento ambiental "verde" y de sus ONGs en América Latina}

El movimiento ambiental, en la sociedad civil de América Latina, pasó por las mismas bien conocidas etapas denominadas "mito de la naturaleza inagotable" (siglo XIX y comienzos del XX), proteccionismo radical (después de la Primera Guerra Mundial y hasta los años 1960s), conservacionismo (1960s-1980s) para llegar, últimamente, a la del utópico desarrollo sostenible (Dourojeanni, 1986). Las primeras ONGs latinoamericanas aparecieron bajo la filosofía proteccionista que, en verdad, fue una respuesta a la descontrolada destrucción de los recursos naturales que había dominado el comienzo de la era industrial y a la inercia total del estado en asuntos ambientales. De esa época son las diversas "sociedades protectoras de la naturaleza” que existieron hasta los años 1960s en casi todos los países de la región. Muy pocas de ellas sobreviven hasta la actualidad, aunque bastante cambiadas, como en el caso de la Fundación Brasileña para la Conservación de la Naturaleza (FBCN). Ellas eran generalmente conformadas por intelectuales prestigiosos y tuvieron un importante papel en la identificación y denuncia de problemas ambientales pero, de otra parte, fueron instituciones poco prácticas y por eso ineficaces. Además, sus percepciones sobre las soluciones eran frecuentemente económica y socialmente inviables.

A partir de los años 1960s, pero especialmente en los años 1970s, floreció el conservacionismo que, en verdad, apenas difiere del "desarrollo sustentable" en el nombre y que reconcilió protección de la naturaleza con desarrollo social y económico. Su máxima expresión escrita, poco antes de ser sustituido por el más atractivo apelativo de desarrollo sostenible, fue la "Estrategia Mundial para la Conservación” (IUCN/PNUMA/WWF, 1980). Este documento, aunque menos promovido y más prudente que el informe de la Comisión Brüntland, conocido como “Nuestro Futuro Común” (WCED, 1987), fue mucho más serio y trascendente. Bajo el concepto conservacionista comenzaron a aparecer ONGs de nuevo cuño en toda América Latina y, así, de finales de los años 1970s hasta comienzos de los años 1990s fueron creadas millares de ONGs ambientalistas. Apenas en el Brasil, en 1995 se contaban 4,000 ONGs ambientales, de las cuales 1563 estaban registradas en el Ministerio del Medio Ambiente (Pizzi, 1995). En el Perú hay 995 ONGs registradas en la Agencia Peruana de Cooperación Internacional, de las que por lo menos el $25 \%$ tiene actividades ambientales, pero hay muchas ONGs que no están incluidas en ese registro.

De esa multitud de ONGs sólo algunas, en general las pioneras de nivel nacional, alcanzaron un nivel de desarrollo significativo y sobreviven hasta la actualidad, pero a cada año nuevas ONGs son creadas. Pizzi (1995), reveló que sólo $30 \%$ de las ONGs brasileñas registradas tenía funcionarios a tiempo parcial o completo y que sólo $2.7 \%$ de ellas tenían más de 5 funcionarios a tiempo completo. Asimismo, el $75 \%$ de esas organizaciones no generaban ningún recurso propio (por ejemplo, a través de cuotas o venta de artículos) y el $59 \%$ de ellas se mantenía exclusivamente en base a donaciones. De otra parte, el $89 \%$ de esas ONGs declaraban que su foco era la educación ambiental, una actividad mal definida y, en muchas formas relativamente fácil de ejecutar con recursos escasos. Otra característica revelada por Pizzi (1995) es que las ONGs tienen muy pocos miembros o ninguno. Las pocas excepciones fueron la SOS Mata Atlántica y el Green Peace, con varios millares cada una.

La situación arriba ejemplificada con datos del Brasil es válida para los demás países de la región. Muchas de las ONGs nacionales más importantes y más influyentes, como ProNaturaleza (Perú) o Funatura (Brasil) simplemente no tienen miembros, excepto los que conforman sus cuerpos directivos ad honorem. Eso se debe a que ellas revisten la figura legal de fundación, supervisadas por el Estado, lo que les permite ofrecer mejores garantías de gestión del dinero donado o recolectado que bajo las formas de 
asociación, instituto u otras, que no son supervisadas ${ }^{1}$. Lamentablemente, la falta de miembros les resta legitimidad y, además, les limita la capacidad de recaudar fondos a través de cuotas.

En los años 1980s el establecimiento y promoción de ONGs nacionales con personalidades locales reconocidamente serias, se convirtió en una prioridad para las grandes ONGs internacionales. Sin ellas, no podrían desarrollar sus programas y proyectos para conservar el patrimonio natural de América Latina. Esta región abandonada de inversiones ambientales internacionales, anteriormente siempre dirigidas al África o al Asia, había sido "descubierta” gracias a diversos estudios científicos y a una visión renovada a partir de la Unión Internacional para la Conservación de la Naturaleza (UICN). Los gobiernos nacionales, desinteresados por el tema ambiental, mal equipados y atravesando penurias económicas severas, no podían asumir sus responsabilidades. Así, el World Wildlife Fund, hoy World Wide Fund For Nature (WWF), creado en 1961 y The Nature Conservancy (TNC), creada en $1951^{2}$, se convirtieron en los padrinos de varias ONGs nuevas, prácticamente por lo menos una en cada país de la región, como Apeco y ProNaturaleza (Perú), Natura (Ecuador), Funatura y Biodiversitas (Brasil), Vida (Honduras), Fundación Neuquén (Argentina), Defensores de la Naturaleza (Guatemala), etc.

El WWF y el TNC, en los años 1980s, manejaban esencialmente el dinero que colectaban entre sus miembros y entre donantes corporativos. Ese dinero era aplicado en América Latina a través de sus ONGs asociadas, las que desarrollaron rápidamente con esos y otros recursos. El WWF nunca se preocupó mucho por la institucionalidad de las ONGs nacionales con las que trabajaba ${ }^{3}$. Bastaba que cumpliera los acuerdos, manejara correctamente los recursos y alcanzara los objetivos de los proyectos. Para eso, especialmente el WWF-US, organizaba con regularidad encuentros con sus asociados para discutir procedimientos y resolver, en buena forma, eventuales conflictos. El TNC tuvo una actitud muchísimo más consecuente pues, además de financiar programas de largo aliento y proyectos, se preocupó grandemente por crear instituciones locales fuertes $y$ financieramente autónomas. El TNC obtuvo de la

\footnotetext{
1 / La verdad es que ProNaturaleza o Funatura, como tantas otras "fundaciones" latinoamericanas, no son realmente fundaciones. Ellas no poseen rentas propias fijas y por eso no distribuyen recursos a otras instituciones para realizar proyectos. Ellas, en general, ejecutan obras directamente con el dinero que recaudan. Cuando creadas, existía la ilusión de que pudieran ser verdaderas fundaciones.

2/ Su Programa Internacional fue creado en 1974.

3 / Una excepción fue el desarrollo del estudio "Estrategia para la Capacitación en Recursos Naturales y Medio Ambiente: Una propuesta para la capacitación de personal y el desarrollo de instituciones ambientales especializadas en América Latina” (1980), desarrollada por el WWF-US a pedido de la USAID, pero que nunca fue aplicada.
}

recientemente creada Fundación MacArthur los recursos para fortalecimiento de un cierto número de ONGs claves de América Latina e, inclusive, destacó sus funcionarios para servir, por plazos largos, en esas ONGs, impulsando la recaudación local de fondos. Este esfuerzo fue evaluado por Myers \& Bucher (1989) que concluyeron que había sido positivo pero que debería continuar por largo tiempo. También recomendaban continuar con la política de exigir "matching fund" (fondos correspondientes), aunque fallaron en reconocer que los fondos aportados por las ONGs nacionales no eran de ellos sino de otras ONGs internacionales. En verdad, las ONGs nacionales raramente consiguieron los tales matching funds de fuentes locales ${ }^{4}$.

Lamentablemente, al final, los esfuerzos del TNC por fortalecer las ONGs nacionales se frustraron en prácticamente todos los casos y, a mediados de los años 1990s, fueron casi abandonados. De una parte, la realidad económica (la famosa "década perdida de la economía”), el comportamiento empresarial poco ético y la baja conciencia ambiental de la población y de los políticos, derrotaron los mejores esfuerzos para asegurar un financiamiento sostenido de las ONGs nacionales. De otra parte, las ONGs nacionales no fueron lo serias ni lo persistentes que deberían haber sido en el tema de asegurar su independencia económica. Éstas, además de los recursos que llegaban a través de las ONGs internacionales mencionadas y otras, también comenzaron a recibir sumas importantes de la cooperación multilateral (NNUU y sus agencias, bancos multilaterales) y bilaterales. En cierta forma, "nadaban" en dinero y sus dirigentes no percibieron la necesidad de asegurar un mínimo de fondos locales para garantizar su independencia y su futuro. Las ONGs internacionales no percibieron que algunas medidas simples podrían haber ayudado mucho a crear institucionalidad, por ejemplo, el apoyo para la compra de locales propios para las ONGs nacionales, que evitarían el drenaje que significa pagar alquileres elevados por locales impropios. Una de las medidas que el WWF y el TNC adoptaron y que mejor ayudaron a las ONGs nacionales fueron los “canjes de deuda por naturaleza”, que aunque eran esencialmente dedicados a acciones específicas eran de largo plazo. Pero, por diversas razones, esta opción no fue extendida a todos los países ni fue renovada en la escala prevista.

Desde el comienzo de los años 1990s pero con mayor intensidad a partir de la segunda mitad de esa década apareció un cambio gradual pero trascendente en el comportamiento de las ONGs internacionales, ya incluyendo entre las tres grandes a Conservation

\footnotetext{
4 / Las excepciones son representadas por entidades como la Fundación $O$ Boticário (Brasil), que poseen fuentes fijas y seguras de recursos propios, en el caso, generados por la empresa que creó la Fundación que separa $1 \%$ de su facturación líquida para inversiones sociales, de lo que el $80 \%$ es para la Fundación.
} 
International (CI), fruto de una escisión dolorosa dentro del TNC, producida en 1987.

\section{De ONGs internacionales a ONGs "transnacionales"}

El cambio de las ONGs internacionales a ONGs transnacionales fue progresivo y se manifestó en diversas formas: (1) su incorporación formal en los países en los que actúan, como ONGs nacionales, aunque su filosofía responde estrictamente a la matriz y a que carecen de autonomía política y financiera; (2) la ejecución directa, por unas ONGs unas más que otras, de sus propios programas y proyectos prescindiendo de las organizaciones nacionales; (3) su actuación como intermediarias financieras entre los donantes multilaterales o bilaterales y las grandes fundaciones (particularmente las fundaciones MacArthur y Moore); (4) su competición con las ONGs nacionales en materia de recaudación de fondos internacionales y, en gran medida, también nacionales y; (5) su competición con las ONGs nacionales en el reclutamiento de personal calificado, en base a mejores ofertas laborales.

El WWF, desde los años 1970s, tenía en algunos países de América Latina agrupaciones afiliadas que tenían el derecho de usar el logotipo del WWF, como fue el caso de Prodena en Perú y Fudena en Venezuela. Pero, esas instituciones eran típicamente nacionales $\mathrm{y}$, de hecho, ellas en general no canalizaban los recursos del WWF, sea internacional o de países como EEUU, que llegaban directamente a otras ONGs nacionales. En este momento, WWF, TNC y CI, cuando incorporados en los países, aunque adopten complementariamente el nombre el país y posean directorios conformados por personalidades nacionales y que la mayor parte de su personal también sea local son, sin mucho disimulo, las propias organizaciones matrices y sus grados de libertad son limitados, especialmente en términos financieros.

Cuando el WWF y CI pasaron a ejecutar directamente sus propios programas y proyectos evidentemente rompieron muchos de sus vínculos con las ONGs nacionales con las que venían trabajando y, en muchos casos, reclutaron el personal de estas, atraídos por mejores condiciones laborales y salariales. Pero, el problema más serio para las ONGs nacionales fue constatar que bajo el nuevo régimen, recursos externos a los que antes tenían acceso directo, ahora pasan por las grandes ONGs transnacionales. En efecto, el volumen de recursos del Grupo del Banco Mundial, de agencias del Sistema de las Naciones Unidas, del Grupo BID, de países desarrollados (EEUU, Alemania, Japón, Holanda) y de otras agencias, como la International Tropical Timber Organization (ITTO) que, en los últimos 10 años, pasaron directa o indirectamente a través de esas ONGs, es enorme. Una excepción fue la USAID que, desde mediados de los años 1980s (Long \& Wise,
1992), con altos y bajos, ya canalizaba parte de sus recursos para biodiversidad por intermedio de las ONGs de EEUU, en gran parte a través de TNC y WWF. Pero, en la actualidad, estas organizaciones y CI se han colocado como intermediarios (en verdad como brokers) casi ineludibles para muchos de los donantes, inclusive para las copiosas donaciones de las fundaciones MacArthur y Moore. En esos casos, aunque las ONGs citadas terminen colaborando con las ONGs nacionales, la intermediación tiene un costo muy elevado.

Lo anterior implica también, que las ONGs nacionales deban competir por recursos con sus antiguas aliadas tanto en el plano internacional como nacional. En efecto, inclusive el TNC que, hasta ahora ha sido mucho más moderado en esa actitud que el WWF y CI, toca frecuentemente las mismas puertas que las ONGs nacionales y, claro, la mayor capacidad de preparar proyectos "vendibles", la enorme experiencia, los contactos y la marca registrada bien conocida de esas organizaciones les dan una ventaja sin par. El WWF por ejemplo, compite directamente en levantar fondos al nivel local. Evidentemente, las grandes empresas transnacionales actuantes en América Latina prefieren hacer aportes a esa transnacional ambiental y a su famoso panda que a las modestas ONGs nacionales. Apoyadas por sus matrices, esas filiales de las ONGs transnacionales poseen todo lo que sus hermanas locales no tienen: oficinas cómodas y bien equipadas, sueldos decentes, desarrollo profesional y seguridad. Así, atraen a los mejores profesionales locales $\mathrm{y}$, rápidamente, producen proyectos y productos de buena calidad.

¿Por qué se produjo ese cambio? Debido a su carácter gradual es difícil identificar causas o justificaciones más importantes que otras, las que además deben haber variado de organización a organización. Pero, sin duda, con relación a la incorporación en los países de América Latina de ONGs internacionales, la principal fue mostrar una “cara” nacional como respuesta a críticas cada día más frecuentes de ultra-nacionalistas como, por ejemplo, los que declaran que "la Amazonia brasileña está siendo colonizada por las ONGs al servicio del imperialismo". Esta es, obviamente, una acusación ridícula, generalmente promovida por madereros y otros explotadores ilegales y amparada por políticos inescrupulosos y militares anticuados. Las ONGs transnacionales saben, obviamente, que su incorporación no va a proporcionarles una recaudación local muy significativa ${ }^{5}$. En cambio, gracias a su nuevo carácter "nacional" obtienen con más facilidad recursos de otras instituciones internacionales y bilaterales. De otra parte, una vez

\footnotetext{
5 / Sin embargo, el WWF-Brasil, por ejemplo, ha recaudado localmente cifras significativas de donaciones de individuos, de afiliados y empresas, entre 2002 y 2004, gracias a una bien llevada campaña (WWF-Brasil, 2004).
} 
incorporadas, es obvio que deben realizar acciones concretas y así comenzaron a ejecutar, ellas mismas, los programas y proyectos que antes realizaban a través de ONGs nacionales.

Organizaciones como WWF y TNC, tradicionalmente, han colectado sus fondos de dos formas: (1) donaciones personales (inclusive herencias millonarias) o de grandes empresas o corporaciones y, (2) centavo a centavo a través de sus amplias membresías. Para eso, además de un cuidadoso trabajo de "enamoramiento" de personalidades ricas o influyentes, se organizaban toda clase de campañas y eventos de recaudación de fondos. Pero, mal que bien, esto debió parecer poco cuando, a partir de los 1990s el interés por el tema ambiental explotó y muchos millones de dólares comenzaron a estar disponibles a través de los bancos multilaterales y las agencias de cooperación al desarrollo. Las ONGs internacionales no tardaron en percibir que, en lugar de apoyar los proyectos de las ONGs nacionales frente a esas agencias, era mejor para ellos convertirse en los receptores "responsables" de dichos recursos que luego, ellos mismos transferirían a sus asociadas nacionales. De esa forma conseguirían crecer mucho más y más rápido que con donaciones privadas. Y así fue $^{6}$.

Lo ocurrido obedece también a otras lógicas: (1) la creciente dificultad de recaudar fondos particulares para acciones en países que los donantes consideran lejanos y, de otra parte, la interminablemente creciente demanda de recursos para la conservación en esos países; (2) el hecho de que, en la práctica, entidades como el WWF gastan la mayor parte de sus recursos recaudados para "conservar la naturaleza" en acciones de tipo esencialmente social y económico (los llamados "integrated conservation development projects" o ICDPs), desincentivando a un gran segmento de donadores (Dourojeanni y Pádua, 2001); (3) la competencia entre ONGs transnacionales que hizo que cuando una obtuvo recursos de ese tipo de fuentes todas se lanzaran en la misma senda; (4) haber caído bajo la influencia de las reglas de la burocracia, a las que ninguna ONG escapa, buscando más dinero, poder e influencia y, claro, aumentando el número de funcionarios y el número y tamaño de las oficinas y; (5) la dificultad de escoger las ONGs que deben ser sus asociados nacionales, ante su proliferación y sus rivalidades, a veces extremas.

Otras causas también pueden anotarse: Las ONGs internacionales, basadas en los países donantes, tienen mayor facilidad para hacer contactos, preparar

\footnotetext{
6 / El autor no tuvo medios, en esta oportunidad, de calcular el porcentaje de recursos que las grandes ONGs transnacionales destinan a América Latina que proceden de fuentes públicas multilaterales o bilaterales o de grandes fundaciones. Pero no tiene duda de que, en la actualidad, gran parte de los recursos que ellas canalizan podrían haber sido obtenidos y los proyectos ejecutados directamente por las ONGs nacionales, sin intermediación.
}

proyectos y someterlos con éxito y premura. También influye el hecho de que esas ONGs, en sus países, son nacionales, inspirando confianza en el gobierno respectivo y en los contribuyentes. Asimismo, los donantes bilaterales y las grandes fundaciones muchas veces prefieren tener a esas ONGs experimentadas como administradores, librándose de problemas, inclusive del problema de escoger la contraparte local.

\section{Las consecuencias financieras y políticas del cambio de estrategia de las ONGs internacionales}

La nueva forma de actuar, el "estilo transnacional” de las ONGs internacionales tuvo $y$ tiene implicaciones sustanciales para el manejo del tema ambiental y para el movimiento ambiental en los países de América Latina. Estas se reflejaron en las finanzas y, en la política.

En materia financiera los impactos fueron: (1) reducción proporcional, de moderada a drástica, de los recursos transferidos por esas ONGs a las ONGs nacionales; (2) dificultad creciente de las ONGs nacionales para obtener recursos para sus actividades; (3) a consecuencia de los dos hechos anteriores, se produjo una caída en muchos casos severa de los presupuestos anuales de las ONGs nacionales, algunas de las cuales arrastran un déficit que las hace bordear la quiebra y; (4) una severa erosión de los recursos que efectivamente llegan a las acciones de campo debido al aumento de un eslabón en la cadena de intermediarios (Figura 1).

ProNaturaleza (Perú), FUNDHAM (Brasil) y Funatura (Brasil), entre docenas más de las mayores ONGs nacionales que trabajan temas de protección de la naturaleza en la región tienen presupuestos actuales que son apenas de 20 a $60 \%$ de lo que eran durante los periodos de apogeo del apoyo de las grandes ONGs internacionales (ProNaturaleza, 2004; Funatura, 2004; FUNDHAM, 2004). Y si no redujeron más sus actividades es porque sustituyeron los recursos perdidos de esas fuentes con otras. Prácticamente todas las ONGs nacionales que trabajan el tema de la protección de la naturaleza pasan por severos aprietos económicos, pagando salarios precarios y, en muchos casos, "prostituyéndose", o sea aceptando realizar operaciones que no se condicen con sus finalidades ni sus objetivos o haciendo trabajos que son mucho más consultorías que obras de interés para la sociedad. Esa situación contrasta, por ejemplo, con la de ONGs que trabajan temas sociales (y en menor grado socioambientales), como el Instituto Socioambiental (ISA) del Brasil cuyo presupuesto aumentó sin sobresaltos en $710 \%$ entre 1995 y 2003, pero que en ese lapso no tuvo entre sus donantes a las tres grandes ONGs internacionales mencionadas (ISA, 2003) y que tampoco debe competir contra ellas. La situación de las ONGs ambientalistas mencionadas asimismo es opuesta a la de instituciones como la Fundación $O$ Boticário de Protección a la Naturaleza (Brasil) cuyo 
presupuesto depende esencialmente de las utilidades de una importante empresa privada y que ha crecido exponencialmente de 1991 a la fecha (Fundação O Boticário, 2004).
Una consultoría financiada por el TNC para evaluar los problemas administrativos de ProNaturaleza reveló que en buena parte ellos se debían a que la propia TNC no aceptaba pagar mas que 6 a $7 \%$ de carga

Figura 1. Los caminos del dinero para medio ambiente (versión muy simplificada)

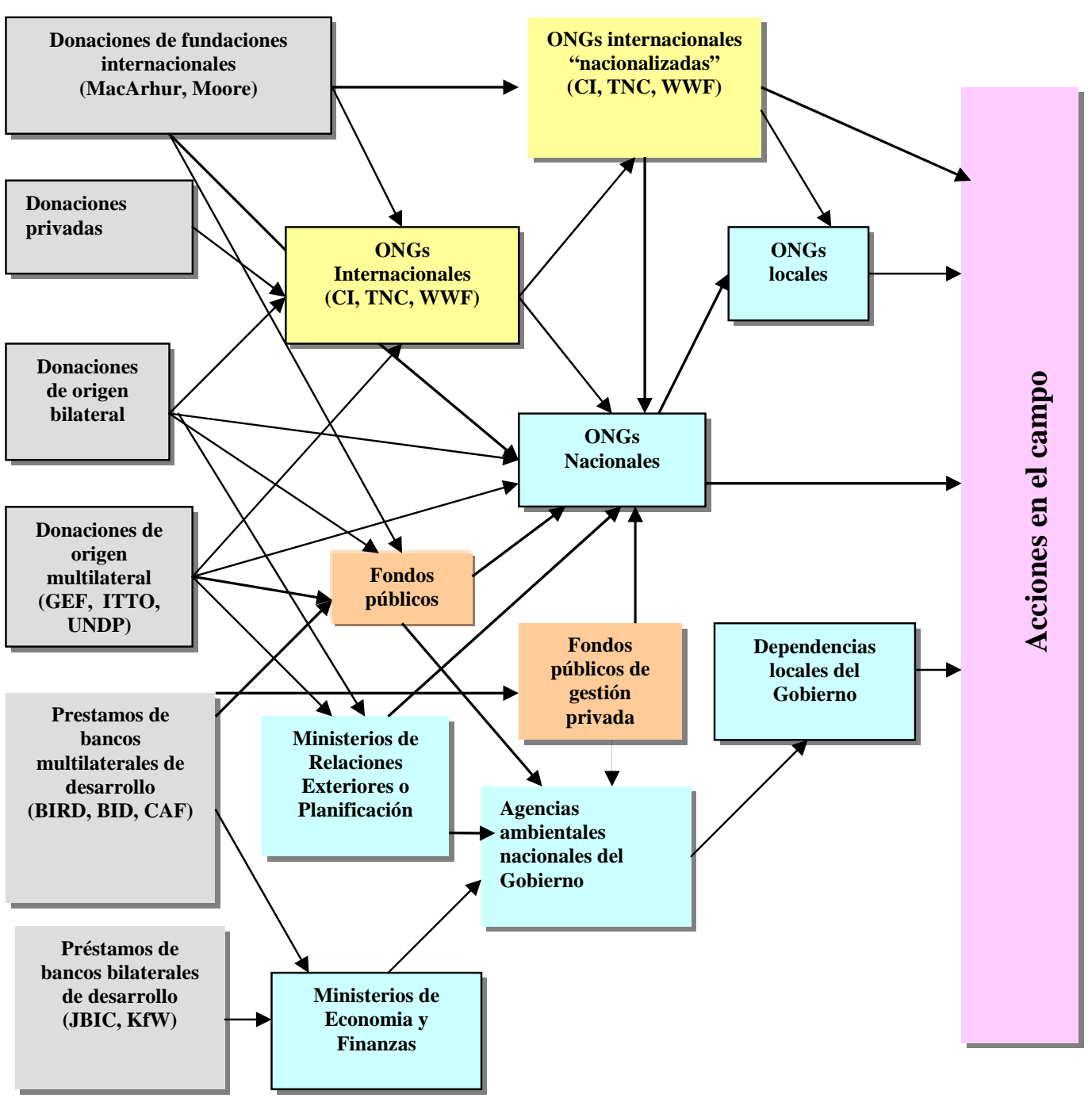

El mal crónico de las ONGs nacionales, al que dicho sea de paso no escapan ni siquiera organizaciones como la propia UICN, es la falta del llamado “core funding” o presupuesto de libre disponibilidad para costear sus gastos operativos institucionales y para desarrollar actividades de su interés exclusivo. Este problema es, en parte, consecuencia de la baja capacidad, o de la incompetencia de las ONGs nacionales para discutir sus costos de administración de proyectos con los donantes que siempre procuran reducirlos al mínimo. administrativa u "overhead” cuando el mínimo justo y necesario debería haber sido el doble (Tressler, 2000). Lo chocante es saber que esa misma ONG recibe fondos de la USAID cobrando $27 \%$ o más de overhead. Recursos de las NNUU apenas autorizan, en general, 3\% de overhead. Eso ocurre pues esas agencias y organizaciones asumen que el overhead debe ser cubierto por las ONGs nacionales, sin querer reconocer que esto es simplemente imposible en las circunstancias actuales. Varias de las ONGs nacionales, ProNaturaleza entre otras, literalmente han 
financiado a las internacionales de esa forma, arrastrando por eso un déficit considerable.

Cuando, por ejemplo, la USAID otorga un apoyo para un programa a través de una ONG internacional que, a su vez, transfiere el recurso a su filial en el país que, luego, utiliza como intermediario una ONG nacional, que a su vez puede utilizar una ONG local existe una severa erosión del dinero debido a las cargas administrativas u overheads al pasar de una entidad a otra. Estas comienzan por el propio donante que reserva un porcentaje (de 2 a 15\%) para monitoreo, supervisión y evaluación. Se estima, en base a resultados de entrevistas de lo que representan estas cargas, al pasar de un intermediario a otro, que apenas de 30 a raramente tanto como $60 \%$ del monto aprobado para la operación, llega efectivamente al campo. El dinero que, en el ejemplo citado, se queda en Washington ${ }^{7}$ y en la filial nacional de la ONG transnacional es improductivo en relación al proyecto perseguido. Si se redujera la intermediación podría aumentarse considerablemente la eficiencia del uso del dinero.

En el campo político es evidente que la nueva estrategia de las ONGs internacionales agrava la falta de libertad de las ONGs locales y del movimiento ambiental nacional para hacer lo que ellos consideran prioritario. Las prioridades son decididas en Washington o New York y en otras capitales, en base a la información y a veces sugerencia de los agentes locales que, a pesar de que muchos son nacionales, fueron escogidos en sus cargos precisamente porque observan la realidad del país en forma consecuente con la filosofía de sus patrones. Eso no está mal y lo contrario sería mucho peor, pero no garantiza que las acciones emprendidas sean las que las ONGs nacionales consideran prioritarias. $\mathrm{Y}$ cuando las ONGs transnacionales ponen, en la línea de frente, personalidades nacionales para discutir prioridades nacionales, ellos suelen llevar las de ganar. Es lo mismo que hacen las grandes corporaciones transnacionales con relación a sus competidores locales.

Así ocurren situaciones más que curiosas, como el actual abandono del Parque Nacional del Manu (Perú), una de las incontestables joyas de las áreas protegidas de América Latina, por todas las ONGs “transnacionales” al unísono. También, así, las ONGs "transnacionales" imponen las modas que los intelectuales de los países ricos inventan a cada año, incluido el desvío de fondos para medio ambiente a la solución de problemas eminentemente sociales, para los que existen otras opciones de atención

\footnotetext{
7 / Eso no es nuevo. En 1995 un estudio de M. Lundberg \& J. L. Garret "A 2020 vision for food, agriculture and the environment" (IFPRI) revelaba que la ayuda externa americana en esos campos generaba empleos en EEUU a razón de un dólar por cada 4 invertidos. $\mathrm{Y}$, en ese estudio, ni se mencionaba el tema de los overheads.
}

(Dourojeanni \& Pádua, 2001). Igualmente, esas ONGs han utilizado recursos excesivos para realizar investigaciones científicas y estudios, hasta por varios millones de dólares, en áreas en las que no existe dinero ni para pagar el mantenimiento mínimo ${ }^{8}$. El resultado es, claro, mucho dinero desperdiciado.

Pero hay más, los funcionarios nacionales de las ONGs transnacionales tienen, en general, un historial personal que les hace ser poco imparciales en sus recomendaciones a la sede de sus organizaciones. A lo largo de sus vidas profesionales hicieron amigos y enemigos y se formaron opiniones firmes sobre los actores del movimiento ambiental. Y, disponiendo del poder, aplican sus criterios sin que exista posibilidad de discusión. Es verdad que funcionarios extranjeros de esas ONGs pueden hacer lo mismo, pero con ellos los riesgos de parcialidad son menores.

En conclusión, la actitud de las ONGs transnacionales está contribuyendo a debilitar y entorpecer un genuino movimiento ambiental nacional $\mathrm{y}$, asimismo, contribuye a un uso no siempre adecuado de los recursos que obtienen $\mathrm{y}$, también, reduce el montante que efectivamente es aplicado para conservar la naturaleza y mejorar el ambiente.

\section{Los pecados capitales de las ONGs nacionales}

Como se señaló antes, las ONGs nacionales son en gran medida responsables de su propia situación. Vale la pena recordar, además, que las grandes ONGs nacionales son muchas veces consideradas, con razón o no según los casos y las percepciones, por las ONGs menores o más nuevas, como acaparadoras de recursos y también como imperialistas ${ }^{9}$.

Las ONGs nacionales son culpables por no haber sabido, a lo largo de sus 20 años o más de existencia, crear o mantener su independencia tanto política como financiera. El dinero, inicialmente recibido en forma fácil de ONGs internacionales y de otras fuentes obnubiló sus dirigentes que abandonaron pronto dos tareas sustanciales: (1) crear una base de miembros grande y coerza que les otorgue legitimidad y, (2) recaudar fondos locales, de libre disponibilidad, suficiente para cubrir la esencia de sus costos operativos (core funding). Porque no lo hicieron se quedaron sometidos a las decisiones de los donantes. Así es como varias de ellas terminaron se prostituyendo en un grado $\mathrm{u}$ otro, ejecutando proyectos indeseados o no recomendables, apenas para poder sobrevivir sin despedir personal o pasar por la

\footnotetext{
8 / Dourojeanni \& Pádua (2001) citan varios casos. En uno de ellos se gastaron US\$3 millones de dólares en estudios para una área protegida en la que no hay dinero ni para pagar el personal mínimo necesario.

9 / En esta nota el autor califica de ONG "nacional” as todas las ONGs del país. Pero existen diferencias substanciales entre las ONGs nacionales, regionales y locales y entre, por ejemplo, una local con contactos internacionales y otra local sin ellos. La verdad es que muchas ONGs nacionales se comportan en relación a las subnacionales del mismo modo que las "transnacionales” con ellos.
} 
vergüenza de reducir su presupuesto. En general, las ONGs de América Latina ni siquiera tuvieron la prudencia de colectar y conservar los fondos necesarios para cubrir los elevados costos que acarrea, por ejemplo, el despido del personal al término de un proyecto. Los costos colaterales del personal son elevadísimos en países como Brasil y Perú y, apenas cubrir indemnizaciones puede significar la quiebra si no fueron previstas (Gouveia \& Brillante, 2005). La falta de recursos propios también explica que los sueldos de los funcionarios que dirigen las ONGs cayeran a niveles muy bajos o que fueran cubiertos asumiendo en paralelo el liderazgo de proyectos que, en verdad, no administran. Líderes mal pagados implican que su competencia también decae y, como se sabe, jefes mediocres implican que toda la organización sigua el mismo padrón. Así, también decayó la cantidad y calidad de proyectos nuevos y el fund raising se hizo cada vez más difícil.

Otro pecado grave de las ONGs nacionales ha sido abandonar, casi totalmente, su misión de advocacy o sea presión política a través de acciones diversas, inclusive comunicados a la opinión pública cuando necesarios. Porque los gobiernos tienen medios para dificultar el financiamiento de ONGs con recursos multilaterales o bilaterales y porque, en otros casos, las ONGs son "agentes" del gobierno para la ejecución de proyectos, dejaron de hacer el monitoreo, la evaluación y las denuncias que éticamente eran necesarias. En esa actitud también influyó, claro, la falta de fondos de libre disponibilidad pues, mal que bien, las denuncias, para ser serias, deben fundamentarse en inversiones previas en investigación. La actitud pasiva de las grandes ONGs nacionales terminó restándoles prestigio nacional e internacional.

Los conflictos poco edificantes entre ONGs nacionales ${ }^{10}$, que en la lucha por la supervivencia hasta ahora no han sabido identificar y respetar sus respectivos nichos de actuación; y el hecho, incontestable, que varias de ellas no pasan de ser un grupo de colegas que hacen consultoría sin pagar impuestos, no ayudaron a crear un ambiente favorable para la recaudación de fondos. Eso, seguramente, ha sido un argumento más para que las ONGs internacionales pasen a actuar como transnacionales.

En el Brasil se ha creado la figura de OSCIP, es decir organización de la sociedad civil de interés público (AED, 2002) que, son ONGs que adaptándose a ciertas reglas y procedimientos pueden recibir dinero público y ejecutar acciones propias de éstos. Esas reglas, además de imponer un severo control público sobre las finanzas, tal como también se aplica a las fundaciones, exige la aceptación de un compromiso de

10 / La Folha de São Paulo (15 de Marzo de 1987) presentó un amplio, esclarecedor y plenamente vigente artículo bajo el titulo "Divergencias emperran atuação dos grupos ecológicos" cooperación que, según muchos, cercena la independencia de la organización. Varias OSCIPs fueron creadas y otras ONGs se transformaron en OSCIPS, especialmente para asuntos sociales. Lamentablemente, hubo varios casos en que fueron descubiertos usos indebidos de los recursos y de los programas, muchas veces con fines políticos partidarios del gobierno de turno.

La mejor prueba de que es posible que las ONGs de la región escapen de los problemas arriba mencionados es, en el Brasil, la SOS Mata Atlántica que, creada en 1986, dispone ahora de 70000 miembros que cotizan regularmente y que, gracias a eso y a donaciones corporativas, posee una independencia económica suficiente como para conducir proyectos muy visibles, que ella misma escoge, sin depender drásticamente de donantes internacionales. También ha desarrollado un importante sistema de aprovechamiento del voluntariado, una área olvidad por otras ONGs.

\section{Conclusión general}

La nueva actitud de las mayores ONGs ambientales internacionales ya tuvo, y si no es remediada, continuará teniendo implicaciones negativas para el movimiento ambiental latinoamericano y para las ONGs nacionales. Las ONGs nacionales tienen gran parte de la culpa de la situación actual pues, desde hace algún tiempo, en cierta medida abandonaron sus ideales originales y su espíritu de lucha decayó, pasando a ser meros ejecutores de proyectos ajenos o casi ajenos.

Las grandes ONGs internacionales, calificadas de transnacionales en este escrito, actúan esencialmente del mismo modo que Curtis \& Steiner (1997) reprochan a las instituciones multilaterales hacer con las mismas ONGs nacionales, en su informe "Partners or hired hands?" ("Socios o solamente mano de obra?"). Aunque en ese informe los autores critican esencialmente el hecho de que las agencias multilaterales tratan a las ONGs como meras empresas de consultoría, las ONGs internacionales a las que ellos mismos pertenecen hoy ignoran la mayor parte de lo que ellos enuncian como ventajas de las ONGs nacionales como: vehículos para movilizar la sociedad civil, no tener fines lucrativos, experiencia de trabajo con comunidades locales, tener un record de éxitos en ejecución de proyectos en el campo, el aporte de recursos en especies y a veces en dinero, efecto multiplicador al involucrar otros aportes, etc.

El autor sabe, por cierto, que las aquí llamadas ONGs "transnacionales" están constituidas esencialmente por personas honestas y llenas de buena voluntad para con el movimiento ambiental latinoamericano. El autor sabe que no son "imperialistas" ni nada parecido, pero si pretende llamar la atención al hecho de que, sin querer queriendo, cada día sus organizaciones merecen más 
ese apelativo. Es pues tiempo de cambiar y de regresar a un balance más equitativo entre el poder del dinero que las ONGs "transnacionales" tienen y que las ONGs latinoamericanas necesitan y, de otra parte, la legitimidad que estas últimas tienen o pueden tener frente al pueblo de sus países y que ninguna ONG internacional podrá suplir.

\section{Recomendaciones}

Las ONGs transnacionales deben revisar profundamente su modo de actuar y, en especial:

1) Evitar actuar como costosos e innecesarios intermediarios entre las fuentes financieras internacionales y las ONGs nacionales. Esas ONGs podrían, claro, dar un valioso servicio guiando y ayudando las ONGs nacionales a obtener dichos recursos, como lo hacían años atrás.

2) Evitar la ejecución directa de programas y proyectos en los países en los que existen ONGs nacionales idóneas $\mathrm{y}$, si no existen, ayudar a crearlas.

3) Disponer en los países en que operan de representaciones, incorporadas o no, que actúen con la modalidad de "embajadas", es decir recabando información, estimulando acciones, canalizando y evaluando las solicitudes y también, monitoreando y supervisando sus propias donaciones. Esto era lo que esas mismas ONGs hacían una década atrás y funcionaba muy bien.

4) Deben re-iniciar sus abandonadas tareas de fortalecimiento institucional de las ONGs nacionales y perseverar en la búsqueda de socios capaces y responsables.

5) Propiciar oportunidades realistas de diálogo franco con las ONGs nacionales, como lo hacían antes, con miras a resolver conflictos y a trazar acciones realmente conjuntas.

Los donantes internacionales, sean multilaterales o bilaterales, así como las grandes fundaciones también deben reconsiderar sus políticas de usar las grandes ONGs transnacionales o sus filiales nacionales como intermediarias. Eso puede ser cómodo para ellas pero haciéndolo contribuyen a agravar el problema y a incumplir una de sus tareas principales que es el fortalecimiento institucional nacional.

Las ONGs nacionales, tan responsables de la situación actual como las anteriores, deben:

1) Recuperar su autonomía política, conociendo y opinando públicamente en forma sustentada sobre los problemas nacionales que son de su competencia y, a la vez, sometiendo los programas y proyectos que corresponden realmente a su finalidad estatutaria.

2) Evitar aceptar y realizar proyectos sugeridos por donantes si es que no corresponden a su propia finalidad o que, en su entender, son inadecuadamente planificados.

3) Mantener una parcela cada vez mayor de su independencia financiera mediante renovados esfuerzos de recaudación de fondos de libre disponibilidad entre sus miembros y al nivel local. Eso implica que, inclusive las fundaciones, deben legitimarse creando, en las formas que la ley permita, una base de miembros o de asociados lo más amplia posible.

4) Exigir en las negociaciones con los donantes $u$ otros aportadores de fondo que los costos administrativos sea cubiertos en forma justa y no practicar el juego de aceptar lo que es obviamente insuficiente para luego usar ardides administrativos que suplan el déficit.

5) En todos los casos construir un fondo especial e intocable para cubrir las obligaciones que demanda la legislación laboral.

6) Aunque un cierto grado de competición entre las ONGs nacionales pueda ser saludable, ésta debe realizarse con atención a la ética y a la sensatez.

7) Las ONGs nacionales deben identificar sus nichos de actuación, bien sea temática o geográfica, y deben atenerse a ellas y respetar las de las otras ONGs. El oportunismo puede acarrear graves conflictos y facilitar o justificar la acción inadecuada de las ONGs transnacionales.

\section{Literatura citada}

AED 2002. Como fundar uma OSCIP? Agencia de Educação para o Desenvolvimento (AED) Brasília, DF.

Chapin M. 2004. A challenge to conservationists World Watch November/December. : 17-31.

Curtis R. \& Steiner A. $1997 . \quad$ Partner or hired hands? Procurement reform for effective colaboration between NGOs and multilateral institutions The case of the Global Environmmental Facility GEF, Washington, DC.

Dourojeanni M. J. 1986. Recursos Naturales, Desarrollo y Conservación en el Perú_ In La Gran Geografia del Perú Ed. Manfer/Mejia Baca,Madrid/Lima. IV: 240.

Dourojeanni M. J. \& Pádua M.T. 2001. Biodiversidade, a Hora Decisiva Editora UFPR, Curitiba.

FUNATURA 2004. Información extraída de relatórios de actividades de 1994 a 2003 Fundação Pró Defesa da Naturaza, Brasilia, DF.

Fundação O Boticário. 2004. Relatórios de Atividades (1991- 2004) Fundação O Boticário de Proteção a Natureza, Curitiba.

Hellinger D. 1997. NGOs and the large aid donnors: Changing the terms of engagement World Development, Pergamon Journals 15(Suplement).: 135-143.

Gouveia K. \& Brilhante S. 2005. ONGs: O Desafio da sustentabilidade In Seminário "Estratégias para o Século XXI para reduzir a pobreza e conservar a natureza na América Sul-Occidental: Rumo a modelos de gestão participativa”, Cobija, Pando (Bolívia), 30 de setiembre al 02 de octubre, 2005. 
ISA. 2003. Relatório Anual de Atividades 2003. Plano Trienal 2002-2004 Instituto Socioambiental, Brasília, DF. $31 \mathrm{pp}$.

Long F.J. \& Wise J. 1992. The Nature Conservancy Graduate School of Business, Stanford University 22p.+ Annexes.

Myers JP. \& Bucher E.G. 1989. A review of nongovermental organizations in tropical America participating in the John D. and Caherine T. MacArthur Foundation's 1985 institutional-building program Washington, DC.

Pizzi P. 1995. O perfil das ONGs brasileiras In Desafios e perspectivas do movimento ambientalista no Brasil Fundação Francisco, Brasília. : 38-45.

ProNaturaleza. 2004. Dos décadas de conservación en el Perú. Los primeros 20 años de Fundación_ProNaturaleza
Fundación Peruana para la Conservación de la Naturaleza, Lima.

Tressler S. 2000. ProNaturaleza fund raising report and strategy ProNaturaleza, Lima 23p.+Anexos.

UICN/PNUMA/WWF. 1980. Estrategia Mundial para la Conservación Unión Internacional para la Conservación de la Naturaleza y sus recursos (UICN), Gland (varios fascículos).

WCED. 1987. Our Common Future United Nations, The World Commission on Environment and Development Oxford University Press, Oxford.

WWF-Brasil. 2004. Relatório de atividades 2004 Brasília, DF 37p.+Anexos.

${ }^{1}$ Presidente de la Fundación Peruana para la Conservación de la Naturaleza (ProNaturaleza), Lima, Perú. Texto presentado al Seminario "Estratégias para o Século XXI para reduzir a pobreza e conservar a natureza na América Sul-Occidental: Rumo a modelos de gestão participativa”, realizado em Cobija, Pando (Bolívia) del 30 de Setiembre al 02 de Octubre, 2005. 